\title{
BMJ Open Knowledge and practice of hand hygiene among hospitalised patients in a tertiary general hospital in China and their attitudes: a cross-sectional survey
}

Yunxia Li, Yaohong Liu, Li Zeng, Chong Chen, Dan Mo, Sue Yuan

To cite: Li Y, Liu Y, Zeng L, et al. Knowledge and practice of hand hygiene among hospitalised patients in a tertiary general hospital in China and their attitudes: a crosssectional survey. BMJ Open 2019;9:e027736. doi:10.1136/ bmjopen-2018-027736

- Prepublication history and additional material for this paper are available online. To view, please visit the journal (http:// dx.doi.org/10.1136/bmjopen2018-027736).

Received 7 November 2018 Revised 26 February 2019 Accepted 21 May 2019

\section{ABSTRACT}

Objectives We aimed to gain a better understanding of patients' practice of hand hygiene $(\mathrm{HH})$ and their knowledge and attitudes.

Design A cross-sectional survey.

Setting A 3500-bed university-affiliated medical hospital in China.

Participants Inpatients and their family members or caregivers.

Methods An anonymous, self-reported questionnaire were used to collect data.

Results A total of 376 questionnaires were issued, and 310 respondents completed it. Of the 310 respondents, $47.4 \%$ had received $\mathrm{HH}$ education, and $13.5 \%$ had a completing understanding of $\mathrm{HH}$. A majority of patients believed that handwashing was important for disease recovery, and that it could prevent infection development. A total of $62.3 \%$ of patients washed their hands $<5$ times a day and $49.0 \%$ spent $<1$ min every time. With regards to the seven steps of handwashing, $96.45 \%$ of the respondents adhered to the first step (washing the palms), but only $20.6 \%$ adhered to the fifth step (thumbs) and $17.7 \%$ to the sixth step (fingertips). Most respondents washed their hands only when visibly dirty. Few patients washed their hands before drinking fluids, and before and after interacting with visitors. HH compliance was lower among intensive care unit patients than medical patients. Conclusions In conclusion, this study demonstrated that patients had a positive attitude towards $\mathrm{HH}$. However, their levels of knowledge and practice were unsatisfactory. A systematical education about patientHH is needed in future to correct this knowledge and behaviour.

\section{INTRODUCTION}

Healthcare-associated infections (HCAIs)

(c) Author(s) (or their employer(s)) 2019. Re-use permitted under CC BY-NC. No commercial re-use. See rights and permissions. Published by BMJ.

Infectious Diseases Department, Xiangya Hospital Central South University, Changsha, China

Correspondence to

Dr Sue Yuan;

248143918@qq.com are major risk factors for the development of sepsis, ${ }^{1}$ which affects $>30$ million patients every year worldwide, leading to 6 million potential deaths. ${ }^{2}$ Both the Centres for Disease Control and Prevention (CDC) and WHO consider hand hygiene $(\mathrm{HH})$ to be the most important factor in the prevention of HCAIs and the spread of pathogens. ${ }^{34}$ The practice of effective $\mathrm{HH}$ plays a key role in the prevention of healthcare-associated sepsis. ${ }^{5}$ Great efforts
Strengths and limitations of this study

- We measured the hand hygiene knowledge, attitude and performance from the prospects of patient view.

- We designed the questionnaire combines both WHO and Centres for Disease Control and Prevention patient hand hygiene-related policies.

- A stratified random sampling method was used in order to make the sample representative.

- This is a single-centre cross-sectional survey, our results may not be applicable to all other institutions.

- There is a need for further observational studies including quantitative hand bacterial cultures to verify the results of this study.

have been made to improve the performance of 'my 5 moments for hand hygiene' among healthcare workers (HCWs), and this has had a global improvement. However, the role of patient hand hygiene $(\mathrm{PHH})$ has been underestimated. Emerging evidence suggests that most infections occur as a result of bacteria present within a patient's own flora as well as bacteria present on surfaces within the healthcare environment ${ }^{6-8}$; improving the $\mathrm{HH}$ of patients has important clinical significance in reducing nosocomial infection, improving the quality of life of patients and reducing the rate of hospitalisation and mortality. ${ }^{9}$ The CDC has therefore proposed nine moments for patients to practice $\mathrm{HH}$ in clinical institutions. ${ }^{10}$ However, $\mathrm{PHH}$ has been neglected in most medical institutions in China, there were no information provided for patient when they admitted. And also there were few studies have investigated PHH in China, with some of them only focusing on the role of patients as monitors or auditors in the improvement of HCW HH compliance. ${ }^{11}$ Thus, the purpose of this cross-sectional study was to investigate inpatient knowledge, as well as the attitudes towards and practice of $\mathrm{PHH}$ during hospital 
stay with non-provision of PHH information. We also aim to characterise and identify some factors influencing practice compliance, which may contribute to the design of effective PHH promotion strategies.

\section{METHODS}

This cross-sectional, single-centre study was performed at a 3500-bed university-affiliated medical hospital between November 2017 and December 2017.

In this study, $\mathrm{PHH}$ was defined as $\mathrm{HH}$ practices performed by a patient on his or her own hands, including handwashing, and the use of alcohol-based hand rubs (ABHRs) and disinfecting wipes. ${ }^{9}$ In certain situations, this care may have to be provided to patients by professional caregivers or family members.

\section{Participants}

The study was conducted in 71 clinical wards, including the departments of internal medicine, surgery, obstetrics and gynaecology, paediatrics and infectious diseases, and intensive care units (ICUs). Outpatient wards, operating rooms, psychiatric wards, isolation wards and emergency rooms were excluded.

Patients were enrolled through a random sampling method using a random number table. First, data on the number of beds in each ward were obtained from the hospital management department, and a total of 3000 of these beds met our inclusion criteria in terms of ward type. Second, according to the largest sample size formula of simple random sampling, with values of $\Pi=0.5, \alpha=0.05$ and $\delta=0.05$, a total sample size of 385 was obtained. After correction, the required sample size was 342 , but taking into consideration a no-response rate of $10 \%$, a total of 376 patients were required. Finally, patients from each ward were randomly selected using an 8:1 proportion.

Hospitalised patients who provided verbal informed consent and agreed to voluntarily participate in this study were included. Exclusion criteria were patients with an admission time $<24$ hours, patients who did not return to their bed due to surgery or transfer to the ICU, and those with mental status changes. Family members or caregivers were enrolled to represent patients to provide patients' demographic information, attitude and the $\mathrm{HH}$ care they have provided to patients in the case of patients with impaired consciousness, who were critically ill or who were under the age of 14 years. Only family members who stayed with the patients in the wards for $>1$ day were enrolled. Visitors, friends and family members who had only short visits with the patients were excluded. The nurses who were in charge of the eligible patients were selected.

\section{Questionnaires}

In this study, the survey instrument was a self-designed structured questionnaire that was based on 'when should you wash your hands' released by the CDC in 2016, ${ }^{10}$ and the 'standard for hand hygiene for health care workers in health care settings' issued by the National Health Commission of the People's Republic of China in 2009. ${ }^{12}$ Experts from the Department of Infectious Diseases were also consulted in this regard. The questionnaire comprised two parts. The first part was designed to allow for the primary nurse to assess the elicited patient disease information, such as diagnosis, whether surgery was performed, or if there was any infection during the hospital stay.

The second part pertaining to $\mathrm{PHH}$ was designed for patients and their families or caregivers, and comprises four sections. Section 1 pertained to patients' demographic data, including ward type, bed number, place of residence, income and number of hospitalisations. Section 2 pertained to caregiver information, such as if the respondent is a family member or caregiver, his/her relationship with the patient, length of hospital stay, education and occupation. Section 3 addressed PHH knowledge and attitudes, while section 4 evaluated patients' practice of $\mathrm{HH}$, including handwashing moments, steps, number of wash times daily, minutes taken every time and ways in which hands were dried. The PHH moments were scaled as 'seldom', 'sometimes', 'often' and 'always'. 'Not applicable' was selected for those who reported that they did not perform the procedure and therefore did not encounter that moment.

\section{Implementation}

The survey was conducted by eight research assistants, all of whom were team members who participated in all study meetings and discussions, who had knowledge on $\mathrm{HH}$ and its association with HCAI and who had received unified training on how to fill out the questionnaire. The research assistants first obtained approval from the head nurses in the study wards, and then obtained informed consent from the participants who were selected according to our design. Participants were informed that the questionnaire content would not involve invasive measurements or invade privacy, and would not cause injury to the body or mind. All eligible patients and their families/caregivers were informed that participation in the study was voluntarily, and that refusal to participate or withdrawal from the study at any point for any reason would not influence medical decisions. The participants were assured that their information would only be used for research and that strict confidentiality would be maintained, as well as that their data would not be used for business or other purposes without their permission. The questionnaires were distributed to patients who were agreed to voluntary participation in research, and were completed by respondents themselves under the instructions of researchers. The questionnaires were distributed and collected on the spot through the questionnaire online platform named "Wen Juan Xin". A small gift (a piece of soap) valued at $\sim \mathrm{US} \$ 0.50$ was given to each respondent who completed the questionnaire. 


\section{Statistical analysis}

Questionnaire data are presented as the number of participants and percentages. A Kruskal-Wallis $\mathrm{H}$ test was applied to analyse the $\mathrm{PHH}$ implementation rate in the different departments. Binary logistic regression analysis was used to identify the demographic predictors for the respondents who had performed $\mathrm{HH}$ in the moment 'after using the toilet, bedpan or commode'. Only those who responded always were included in the analysis. Univariate analysis by non-conditional logistic regression was used to compare each demographic variable in the different groups. Variables with a $\mathrm{p}<0.10$ were further tested in the multivariate logistic regression analysis by the enter method. A two-tailed $p$ value of 0.05 was considered statistically significant.

\section{RESULTS}

\section{Population characteristics}

A total of 376 questionnaires were issued, and 310 respondents, including 242 patients $(78.1 \%)$ and 68 family members/caregivers $(21.9 \%)$, completed the questionnaire. The total response rate was $82.4 \%$ (310 of 376). The Cronbach's alpha of the questionnaire is 0.867 , which indicate a good reliability of this self-designed questionnaire. The respondents' characteristics are summarised in table 1. A total of $46.8 \%$ of the participants were women, and most of them $(86.8 \%)$ were married. The majority $(79.7 \%)$ had a high school education or lower. More than half of the participants $(64.5 \%)$ were urban or town dwellers, and a similar proportion $(66.5 \%)$ had an annual income $<50000 ¥$ ( US\$7987). Most respondents $(62.3 \%)$ had been hospitalised previously, and $27.7 \%$ reported having an infection at present.

\section{Patients' performance of $\mathrm{HH}$ and their knowledge and attitudes}

Most of the participants (72.2\%) reported that they did not know about HH knowledge or knew very little about it. Less than half $(47.4 \%)$ of the respondents had received HH education before; of them, HCWs $(95,35.6 \%)$ and television $(76,28.5 \%)$ were the main resources. A majority $(94.2 \%)$ of the participants believed that handwashing was important for disease recovery, and almost the same percentage $(93.2 \%)$ of them believed that handwashing could prevent infection spread among patients.

More than half $(62.2 \%)$ of the patients washed their hands $<5$ times a day, and approximately half $(49.0 \%)$ of them spent $<1 \mathrm{~min}$ washing their hands every time. Washing hands under flowing water $(64.7 \%)$ was the main route of washing, compared with washing in a basin or using ABHRs; however, only $13.4 \%$ and $25.6 \%$ of the patients used hand sanitizers and soap, respectively. A total of $41.9 \%$ of the respondents reported that they had a dedicated hand towel, but only $20.0 \%$ and $21.6 \%$, respectively, chose a dedicated hand towel or tissue to wipe their hands (table 2).

\begin{tabular}{|c|c|}
\hline Characteristic & Participants (\%) \\
\hline \multicolumn{2}{|l|}{ Identity of the respondents } \\
\hline Patients & $242(78.1)$ \\
\hline Family members/caregivers & $68(21.9)$ \\
\hline \multicolumn{2}{|l|}{ Sex } \\
\hline Female & $145(46.8)$ \\
\hline Male & 165 (53.2) \\
\hline \multicolumn{2}{|l|}{ Age, years } \\
\hline$<30$ & $57(18.4)$ \\
\hline $30-39$ & $34(11.0)$ \\
\hline $40-49$ & $56(18.1)$ \\
\hline $50-59$ & $72(23.2)$ \\
\hline$\geq 60$ & $91(29.4)$ \\
\hline \multicolumn{2}{|l|}{ Education level } \\
\hline Primary or below & $77(24.8)$ \\
\hline Junior high school & $88(28.4)$ \\
\hline Senior high school & $62(20.0)$ \\
\hline Technical secondary school & $20(6.5)$ \\
\hline College & $34(11.0)$ \\
\hline Undergraduate & $28(9.0)$ \\
\hline Postgraduate or above & $1(0.3)$ \\
\hline \multicolumn{2}{|l|}{ Occupation } \\
\hline Farmer & $67(21.6)$ \\
\hline Workman & $27(8.7)$ \\
\hline Clerk & $47(15.2)$ \\
\hline Medical staff & $2(0.6)$ \\
\hline Teacher & $3(1.0)$ \\
\hline Student & $13(4.2)$ \\
\hline Freelancer & $34(11.0)$ \\
\hline Unemployed & $45(14.5)$ \\
\hline Retiree & $72(23.2)$ \\
\hline \multicolumn{2}{|l|}{ Place of residence } \\
\hline Urban & $147(47.4)$ \\
\hline Town & $53(17.1)$ \\
\hline Village & $110(35.5)$ \\
\hline \multicolumn{2}{|l|}{ Income $\left(¥ /\right.$ year) ${ }^{*}$} \\
\hline$<50000$ & $206(66.5)$ \\
\hline $50000 \sim 100000$ & $80(25.8)$ \\
\hline $100000 \sim 200000$ & $18(5.8)$ \\
\hline$>200000$ & $6(1.9)$ \\
\hline \multicolumn{2}{|l|}{ No of hospitalisations } \\
\hline 1 & $117(37.7)$ \\
\hline 2 & $74(23.9)$ \\
\hline$\geq 3$ & $119(38.4)$ \\
\hline \multicolumn{2}{|c|}{$\begin{array}{l}\text { The length of hospital stay at the time the } \\
\text { questionnaire was completed (days) }\end{array}$} \\
\hline $1-3$ & $67(21.6)$ \\
\hline $4-6$ & $107(34.5)$ \\
\hline
\end{tabular}




\begin{tabular}{|cc|}
\hline Table 1 Continued & \\
\hline Characteristic & Participants (\%) \\
\hline $7-9$ & $49(15.8)$ \\
\hline $10-13$ & $51(16.5)$ \\
$\geq 14$ & $36(11.6)$ \\
\hline Ward & \\
\hline Medical ward & $110(35.5)$ \\
\hline Surgical ward & $144(46.5)$ \\
\hline Obstetrics/gynaecology ward & $23(7.4)$ \\
\hline Paediatric ward & $9(2.9)$ \\
\hline Infectious diseases ward & $15(4.8)$ \\
\hline Intensive care unit & $9(2.9)$ \\
Was surgery performed this time? & $132(42.6)$ \\
\hline Yes & $178(57.4)$ \\
\hline No & $86(27.7)$ \\
\hline Is there any infection? & $224(72.3)$ \\
\hline Yes & \\
\hline No & \\
\hline
\end{tabular}

*50 000¥ $\approx$ US $\$ 7209$.

\section{Patients' practice of the 'seven steps to handwashing'}

The results of patients' practice of the seven steps to handwashing are displayed in online supplementary figure 1 . Most respondents washed their hands with adherence to the first step (rub palms together: 96.45\%, 299 of 310). More than half of them practiced the second step (rub the back of both hands: $66.13 \%, 205$ of 310) and third step (interlace fingers and rub hands together: $66.77 \%$, 207 of 310). A slightly lower number of participants (56.77\%, 176 of 310) adhered to the seventh step (rub both wrists in a rotating manner). The implementation rates of the fourth step (interlock fingers and rub the back of fingers of both hands: $26.77 \%, 83$ of 310 ), and sixth step (rub fingers on palm for both hands: 20.65\%, 64 of 310) were lower. However, the fifth step (rub thumb in a rotating manner followed by the area between index finger and thumb for both hands) had the worst execution rate $(17.74 \%, 55$ of 310$)$.

\section{PHH moments}

Three-quarters $(75.8 \% ; 235$ of 310) of the respondents washed their hands after using the toilet/bedpan/ commode, and $86.1 \%$ washed their hands when they were visibly dirty (table 3 ). Approximately half $(47.7 \%$ ) of the patients washed their hands before touching any breaks in the skin, whereas the implementation rates before any care procedures $(19.0 \%, 59$ of 310) and dialysis/contact with intravenous lines or other tubes $(19.7 \%, 61$ of 310$)$ were low. The performance of handwashing before drinking fluids $(11.0 \%, 34$ of 310$)$, as well as before and after interacting with visitors $(11.9 \%, 37$ of 310 vs $13.2 \%$, 41 of 310 ) was also very low.
Table 2 Performance of hand hygiene and knowledge and attitudes among the 310 included patients

\section{Items}

Total n (\%)

Knowledge and attitude

Have you received any education related to hand hygiene?

$\begin{array}{ll}\text { Yes } & 147(47.4) \\ \text { No } & 163(52.6)\end{array}$

$\begin{array}{ll}\text { Hand hygiene knowledge sources } & \\ \text { Television } & 76(28.5) \\ \text { Newspaper } & 20(7.5) \\ \text { Magazine } & 18(6.7) \\ \text { Internet } & 37(13.9) \\ \text { Medical staff } & 95(35.6) \\ \text { Other } & 21(7.9)\end{array}$

Do you know anything about hand hygiene?

$\begin{array}{lr}\text { Do not know } & 126(40.6) \\ \text { A little } & 98(31.6) \\ \text { Most } & 44(14.2) \\ \text { All } & 42(13.5)\end{array}$

\begin{tabular}{|c|c|}
\hline $\begin{array}{l}\text { Is hand } \\
\text { disease }\end{array}$ & \\
\hline Yes & $292(94.2)$ \\
\hline No & $18(5.8)$ \\
\hline Can har & \\
\hline Yes & 289 (93.2) \\
\hline No & $21(6.8)$ \\
\hline
\end{tabular}

How many times do you wash your hands every day?

\begin{tabular}{lr}
$\leq 2$ & $48(15.5)$ \\
$3 \sim 5$ & $145(46.8)$ \\
$6 \sim 10$ & $69(22.3)$ \\
$>10$ & $48(15.5)$ \\
How long does it take to wash your hands every & \\
time? & \\
$<1$ min & $152(49.0)$ \\
1 2 min & $135(43.5)$ \\
$\geq 2$ min & $23(7.4)$ \\
Handwashing ways & \\
\hline Wash basin & $560(18.9)$ \\
\hline Flowing water & $1913(64.7)$ \\
Alcohol-based hand rub & $484(16.4)$ \\
Handwashing products* & \\
\hline Tap water only & $1797(46.6)$ \\
\hline Hand sanitizer & $516(13.4)$ \\
\hline Soap & $987(25.6)$ \\
\hline Alcohol-based hand rub & $555(14.4)$ \\
\hline Ways in which you wipe your hands* & \\
\hline Hand towel & $919(20.0)$ \\
\hline Any towel & \\
\hline
\end{tabular}

Continued 


\begin{tabular}{|cc|}
\hline Table 2 Continued & Total $\mathbf{n}(\%)$ \\
\hline Items & $1012(21.6)$ \\
\hline Disposable tissues & $410(8.8)$ \\
\hline Clothes on my body & $873(18.7)$ \\
\hline Wave hands in the air & $588(12.6)$ \\
\hline Face towel & \\
\hline Do you have a dedicated hand towel? & $130(41.9)$ \\
\hline Yes & $180(58.1)$ \\
\hline No & \\
\hline Times of hand towel washes every day & $10(7.7)$ \\
\hline 0 & $32(24.6)$ \\
\hline 1 & $29(22.3)$ \\
\hline 2 & $25(19.2)$ \\
\hline 3 & $27(20.8)$ \\
\hline 4 & $7(5.4)$ \\
\hline Wash once every few days
\end{tabular}

*'Handwashing ways', 'handwashing products' and 'ways in which you wipe your hands' these three items are multiple topics, so each number of respondents is over the total number of respondents.

\section{PHH moments in different departments}

Participants in the Department of Internal Medicine had a relatively high execution rate of $\mathrm{HH}$ when their hands were visibly dirty $(96.4 \%, 106$ of 110), before eating $(82.7 \%, 91$ of 110$)$ and before touching any breaks in the skin $(71.8 \%, 79$ of 110). Those in the Department of Surgery tended to wash their hands after using the toilet/bedpan/commode $(94.4 \%, 136$ of 144) and after coughing, sneezing or touching the nose or mouth $(50.7 \%, 73$ of 144). Those in the Department of Infectious
Diseases had good performance rates of handwashing before interacting with visitors $(40.0 \%, 6$ of 15) (table 4$)$. There were significant differences in this regard between the different departments in the Kruskal-Wallis $\mathrm{H}$ test $(\mathrm{H}=19.838, \mathrm{p}=0.001)$.

\section{Significant predictors of PHH moments}

A majority of the respondents $(75.8 \%, 235$ of 310) always performed $\mathrm{HH}$ after using the toilet/bedpan/commode (table 5), and the univariate analysis identified one significant predictor: very few ICU patients practiced $\mathrm{HH}$ compared with medical patients $(\mathrm{OR}=0.08,95 \%$ CI 0.02 to $0.41, \mathrm{p}=0.002)$. In the multivariate analysis, we found two significant variables: being a farmer rather than a clerk (adjusted $\mathrm{OR}=0.18,95 \%$ CI 0.05 to $0.61, \mathrm{p}=0.004$ ) and being a freelancer (adjusted $\mathrm{OR}=0.18,95 \% \mathrm{CI} 0.05$ to $0.62, \mathrm{p}=0.007)$. Medical patients had a higher HH performance rate than those in the Department of Obstetrics-Gynaecology (adjusted $\mathrm{OR}=0.18,95 \%$ CI 0.04 to 0.80 , $\mathrm{p}=0.02$ ) and ICU (adjusted $\mathrm{OR}=0.06,95 \%$ CI 0.01 to 0.45 , $\mathrm{p}=0.006)$.

\section{DISCUSSION}

In the present study, we examined hospitalised patients' knowledge of, attitudes towards and practice of HH. Our findings demonstrate that although patients had a positive attitude towards $\mathrm{HH}$, their knowledge was insufficient, consisting with Cheng $e t a l$ s research. ${ }^{13}$ The social desirability factor might be operating, the hospital we involved attaches great importance to HCW HH and has implemented the WHO's multimodal $\mathrm{HH}$ improvement strategies ${ }^{14}$; therefore, the participants were in an atmosphere in which the importance of $\mathrm{HH}$ is highlighted daily, leading them to believe in its importance. However,

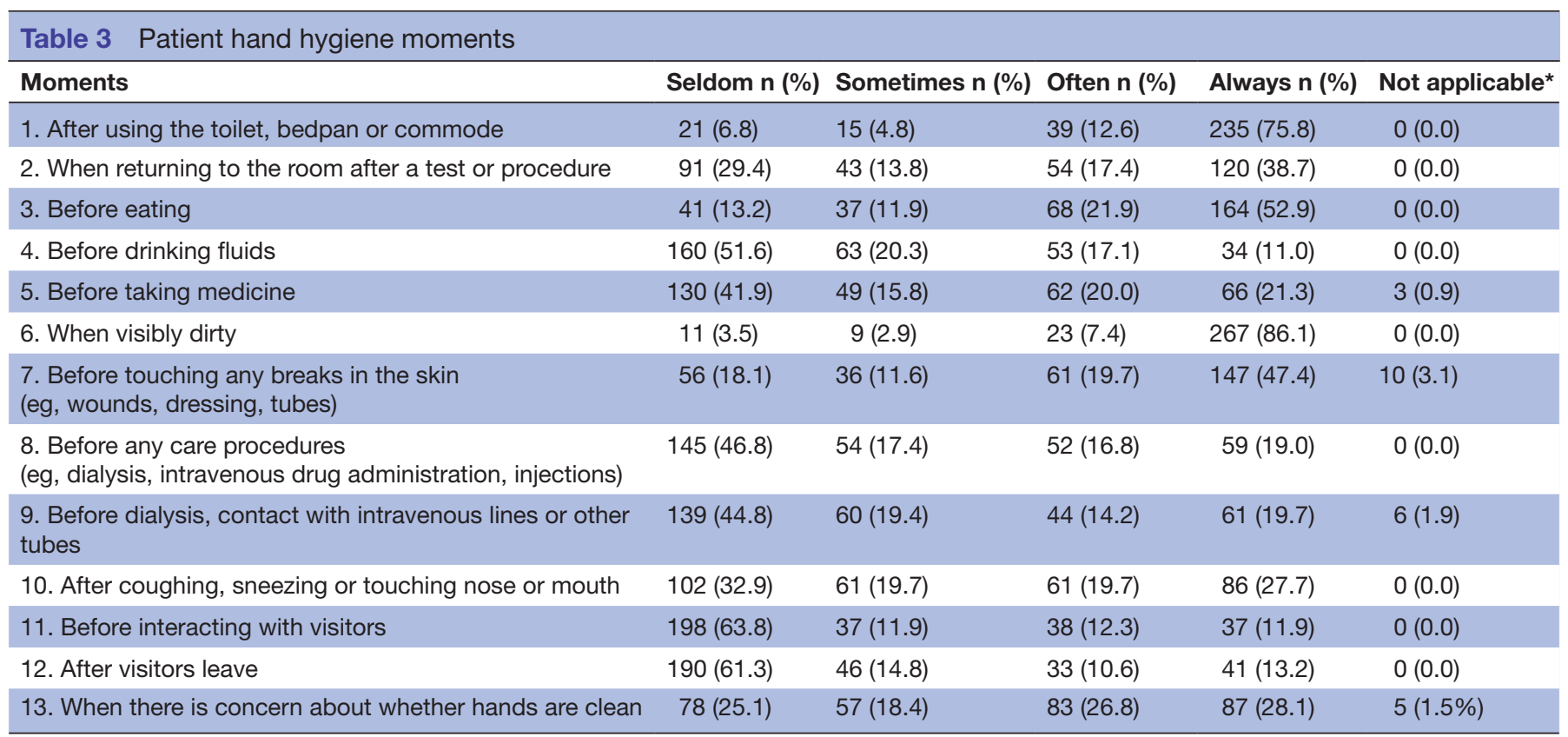

*'Not applicable' represents patients who reported that they did not perform the procedure and therefore did not encounter that moment. 


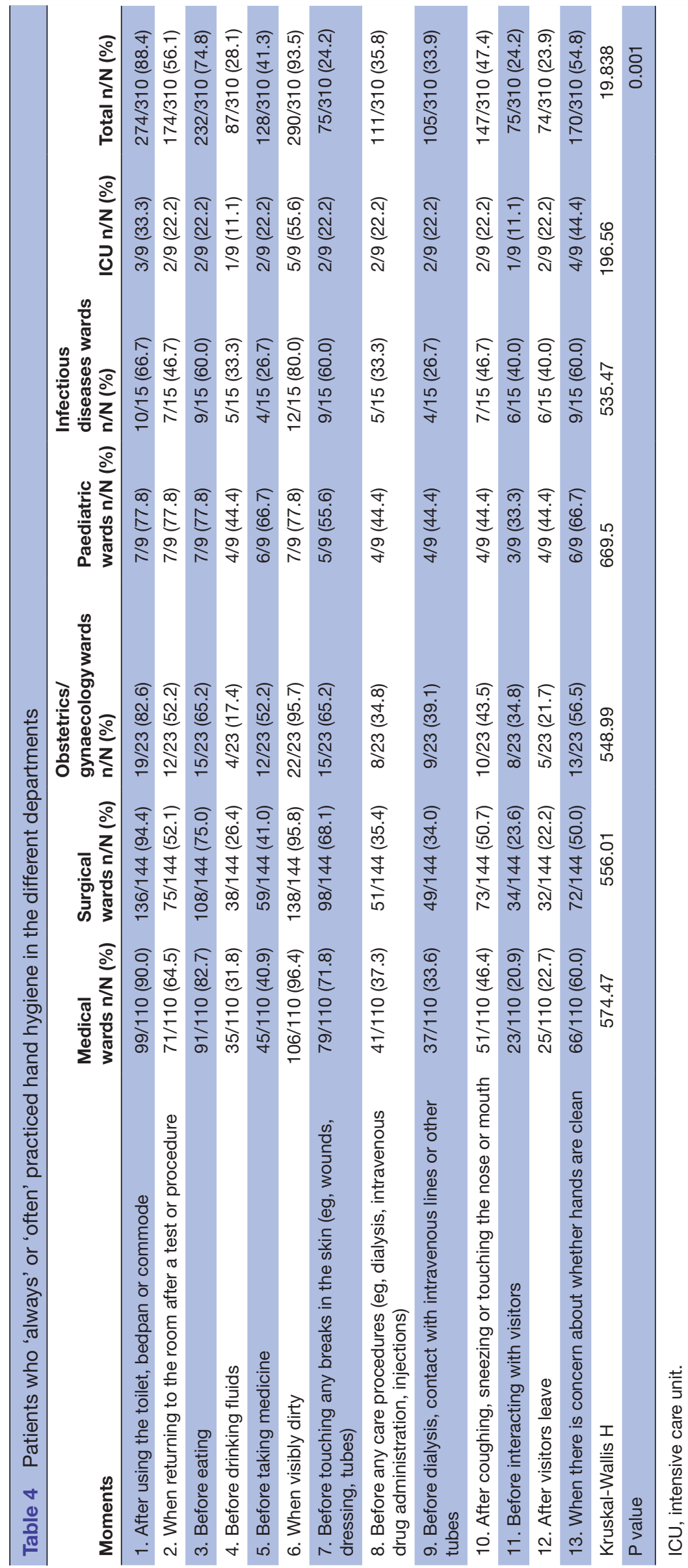


Table 5 Identity of participants who 'always' performed hand hygiene after using the toilet, bedpan or commode using the characteristics of the patients and their family members of caregivers

\begin{tabular}{|c|c|c|c|c|c|}
\hline \multirow[b]{2}{*}{ Characteristic } & \multirow{2}{*}{$\begin{array}{l}\text { Always perform hand } \\
\text { hygiene } \mathrm{n} / \mathrm{N}(\%)\end{array}$} & \multicolumn{2}{|l|}{ Unadjusted OR } & \multicolumn{2}{|l|}{ Adjusted OR } \\
\hline & & OR (95\% Cl) & $P$ value & OR $(95 \% \mathrm{Cl})$ & $P$ value \\
\hline \multicolumn{6}{|l|}{ Identity of the respondents } \\
\hline Patient & $186 / 242(76.9)$ & 1 & & & \\
\hline Family members/caregivers & 49/68 (72.1) & $0.78(0.42$ to 1.43$)$ & 0.42 & & \\
\hline \multicolumn{6}{|l|}{ Sex } \\
\hline Male & $125 / 165(75.8)$ & 1 & & & \\
\hline Female & $110 / 145(75.9)$ & 0.99 (0.59 to 1.67$)$ & 0.98 & & \\
\hline \multicolumn{6}{|l|}{ Age, years } \\
\hline$<30$ & $39 / 57(68.4)$ & 1 & & & \\
\hline $30-39$ & 28/34 (82.4) & 2.15 (0.76 to 6.12$)$ & 0.15 & & \\
\hline $40-49$ & $43 / 56(76.8)$ & 1.53 (0.66 to 3.52$)$ & 0.32 & & \\
\hline $50-59$ & $54 / 72(75.0)$ & 1.39 (0.64 to 3.00$)$ & 0.41 & & \\
\hline$\geq 60$ & 71/91 (78.9) & 1.64 (0.78 to 3.46$)$ & 0.20 & & \\
\hline \multicolumn{6}{|l|}{ Education level } \\
\hline Primary or below & $59 / 77(76.6)$ & 1 & & & \\
\hline Junior high school & $59 / 88(67.0)$ & $0.62(0.31$ to 1.24$)$ & 0.18 & & \\
\hline Senior high school & $51 / 62(82.3)$ & 1.41 (0.61 to 3.27$)$ & 0.42 & & \\
\hline Technical secondary school & $14 / 20(70.0)$ & 0.71 (0.24 to 2.12$)$ & 0.54 & & \\
\hline College & 28/34 (82.4) & 1.42 (0.51 to 3.98$)$ & 0.50 & & \\
\hline Undergraduate & $23 / 28(82.1)$ & 1.40 (0.47 to 4.22$)$ & 0.55 & & \\
\hline Postgraduate or above & $1 / 1(100)$ & l & 1.00 & & \\
\hline \multicolumn{6}{|l|}{ Occupation } \\
\hline Farmer & 56/67 (83.6) & 1 & & 1 & \\
\hline Workman & 23/27 (85.2) & 1.13 (0.33 to 3.92$)$ & 0.85 & 0.85 (0.21 to 3.39$)$ & 0.82 \\
\hline Clerk & $34 / 47$ (72.3) & 0.51 (0.21 to 1.28$)$ & 0.15 & $0.18(0.05$ to 0.61$)$ & 0.006 \\
\hline Medical staff & $2 / 2(100)$ & I & 1.00 & I & 1.00 \\
\hline Teacher & 2/3 (66.7) & 0.39 (0.03 to 4.72$)$ & 0.46 & 0.15 (0.01 to 2.26$)$ & 0.17 \\
\hline Student & $8 / 13(61.5)$ & 0.31 (0.09 to 1.14$)$ & 0.08 & $0.22(0.04$ to 1.24$)$ & 0.09 \\
\hline Freelancers & 23/34 (67.6) & 0.41 (0.16 to 1.08$)$ & 0.07 & 0.18 (0.05 to 0.62$)$ & 0.007 \\
\hline Unemployed & $34 / 45(75.6)$ & 0.61 (0.24 to 1.55$)$ & 0.30 & $0.58(0.21$ to 1.61$)$ & 0.29 \\
\hline Retiree & 53/72 (73.6) & 0.55 (0.24 to 1.26$)$ & 0.16 & 0.36 (0.12 to 1.08$)$ & 0.07 \\
\hline \multicolumn{6}{|l|}{ Place of residence } \\
\hline Urban & 117/147 (79.6) & 1 & & & \\
\hline Town & $37 / 53(69.8)$ & 0.59 (0.29 to 1.21$)$ & 0.15 & & \\
\hline Village & $81 / 110(73.6)$ & $0.72(0.40$ to 1.28$)$ & 0.26 & & \\
\hline \multicolumn{6}{|l|}{ Income (¥/year) } \\
\hline$<50000$ & 153/206 (74.3) & 1 & & & \\
\hline $50000 \sim 100000$ & $61 / 80(76.3)$ & 1.11 (0.61 to 2.03 ) & 0.73 & & \\
\hline $100000 \sim 200000$ & $16 / 18(88.9)$ & 2.77 (0.62 to 12.46$)$ & 0.18 & & \\
\hline$>200000$ & 5/6 (83.3) & $1.73(0.20$ to 15.16$)$ & 0.62 & & \\
\hline \multicolumn{6}{|l|}{ No of hospitalisations } \\
\hline 1 & $87 / 117(74.4)$ & 1 & & & \\
\hline 2 & $59 / 74(79.7)$ & 1.36 (0.67 to 2.74$)$ & 0.40 & & \\
\hline$\geq 3$ & $89 / 119(74.8)$ & 1.02 (0.57 to 1.84$)$ & 0.94 & & \\
\hline \multicolumn{6}{|c|}{$\begin{array}{l}\text { The length of hospital stay at the time the } \\
\text { questionnaire was completed (days) }\end{array}$} \\
\hline $1-3$ & 22/67 (32.8) & 1 & & & \\
\hline $4-6$ & $32 / 107$ (29.9) & 0.87 (0.45 to 1.68$)$ & 0.69 & & \\
\hline
\end{tabular}


Table 5 Continued

\begin{tabular}{|c|c|c|c|c|c|}
\hline \multirow[b]{2}{*}{ Characteristic } & \multirow{2}{*}{$\begin{array}{l}\text { Always perform hand } \\
\text { hygiene } \mathrm{n} / \mathrm{N}(\%)\end{array}$} & \multicolumn{2}{|l|}{ Unadjusted OR } & \multicolumn{2}{|l|}{ Adjusted OR } \\
\hline & & OR $(95 \% \mathrm{Cl})$ & $P$ value & OR $(95 \% \mathrm{Cl})$ & $P$ value \\
\hline $7-9$ & $13 / 49(26.5)$ & 0.74 (0.33 to 1.67$)$ & 0.47 & & \\
\hline$\geq 14$ & $9 / 36(25.0)$ & 0.68 (0.27 to 1.70$)$ & 0.41 & & \\
\hline \multicolumn{6}{|l|}{ Ward } \\
\hline Obstetrics/gynaecology ward & $14 / 23(60.9)$ & $0.43(0.17$ to 1.13$)$ & 0.09 & $0.18(0.04$ to 0.80$)$ & 0.02 \\
\hline Paediatric ward & $6 / 9(66.7)$ & 0.56 (0.13 to 3.40$)$ & 0.43 & 0.95 (0.12 to 7.39$)$ & 0.96 \\
\hline Infectious diseases ward & $10 / 15(66.7)$ & $0.56(0.17$ to 1.79$)$ & 0.33 & 0.51 (0.13 to 2.04$)$ & 0.34 \\
\hline $\mathrm{ICU}$ & $2 / 9(22,2)$ & 0.08 (0.02 to 0.41$)$ & 0.002 & 0.06 (0.01 to 0.45$)$ & 0.006 \\
\hline \multicolumn{6}{|l|}{ Is there any infection? } \\
\hline No & $171 / 224(76.3)$ & 1 & & & \\
\hline Yes & 64/86 (74.4) & 1.11 (0.63 to 1.97$)$ & 0.72 & & \\
\hline
\end{tabular}

$\mathrm{ICU}$, intensive care unit.

due to non-provision of any $\mathrm{PHH}$ information in daily life, nor in hospital after admitted, they were unaware of when and how to wash their hands in clinical practice.

Patients' performance of $\mathrm{HH}$ is poor, and the existing facilities and products are routinely underutilised, consistent with the findings of previous studies. ${ }^{15}$ Although the WHO's multimodal $\mathrm{HH}$ improvement strategies have been implemented by our hospital's infection control committee with the provision of sinks and wash basins for the performance of soap-and-water cleaning in every patient's room, and the provision of ABHR for waterless hand cleaning in the rooms and corridors for all HCWs and patients, ${ }^{14}$ the frequency and duration of handwashing were not satisfactory in this study. A systematical education about $\mathrm{PHH}$ seems necessary, not only for medical staff but also for patients themselves. It is of great significance for patients to realise their own behaviour for the prevention and control of nosocomial infection and the promotion of their own safety. Staff should receive education on the importance of $\mathrm{PHH}$ in the prevention of hospital-acquired infection; and staff need to be instructed to provide verbal PHH education to all newly admitted patients, and to provide reminders, assistance and encouragement for PHH practice. ${ }^{16}{ }^{17}$ In addition, it is also important to ensure that HH products—-such as alcohol-based hand wipes or ABHR-are accessible to patients who are bedridden and are unable to get to the sink. ${ }^{18}{ }^{19}$ Staff or family members should be instructed to provide assistance to improve $\mathrm{PHH}$ opportunities. $^{18}$

Hands were washed most frequently when they were visibly dirty and after using the toilet, but less frequently before drinking fluids and taking medicine, which would be the optimal time for the prevention of fecal-oral transmission. In this study, $75.8 \%$ of the participants washed their hands after using the toilet/bedpan/commode, but only $11.0 \%$ of them washed their hands before drinking fluids. Similar results have been observed in other study on patients in transplant units. ${ }^{20}$ Hospital environments are often contaminated with hospital-acquired pathogens,${ }^{16-18}$ therefore, there is a need for education campaigns aimed at patient-initiated $\mathrm{HH}$ and $\mathrm{HH}$, that is, directly observed before meals and the intake of medications during hospitalisation. ${ }^{21} 22$

Our results also revealed that only $11.9 \%$ of the patients washed their hands before interacting with visitors and $13.2 \%$ washed their hands after the visitors left. Visitors may be vectors of pathogenic organisms that are potentially dangerous, particularly to immunocompromised patients. ${ }^{23}$ If visitors carry certain pathogenic organisms on their hands and do not perform $\mathrm{HH}$ on entry to the hospital, vulnerable patient populations may be at an increased risk for infection if they do not wash their hands after the visitors leave. ${ }^{24}$ Thus, to win the battle against HCAIs, there is a need for coordinated effort to enforce $\mathrm{HH}$ that includes patients, as well as their families, and visitors. ${ }^{25}$ In addition to providing better signage and education among care providers, ${ }^{26}{ }^{27}$ other hospital approaches, such as the installation of more strict visiting infrastructure (ie, ICU doors that will not open if ABHR is not used) might be considered. ${ }^{23}$

This study resulted in some significant findings. Patients' performance about $\mathrm{PHH}$ are differences in different departments. Patients in 'medical department' showed significantly higher PHH performance compared with those in 'Department of Obstetrics/Gynaecology'. 
Patients activity and severity of illness may be working, patients in medical department are mostly treated conservatively, their activity are less restricted than those in Department of Obstetrics/Gynaecology, who may need absolute bed rest because of gynaecological surgery or give birth to a child just now; In addition, Chinese traditional concept may be another factor, which holds that women should not be exposed to cold water after surgery or after childbirth, which may also reduce the practice of hand washing.

The most significant findings being that ICU patients rarely practice $\mathrm{HH}$ compared with those in other departments. This is not surprising as patients in the ICU are generally critically ill or unconsciousness, they cannot wash their hands by themselves. Even the assistance of professional caregivers does not seem to work. This suggests the importance of the role of caregivers in ensuring adequate $\mathrm{HH}$ in such functionally dependent patients. To the best of our knowledge, this study is the first to provide data on ICU PHH, since most previous studies on ICU HH focused on HCWs or patients' families. ${ }^{23}{ }^{28}$ Considering that multidrug-resistant Acinetobacter baumannii infection are highly in $\mathrm{ICU}^{29}$ and ICU patients are the most susceptible populations to nosocomial infections, ${ }^{30}$ attention must be given to improving their adherence to $\mathrm{HH}$ rules to reduce hospital infections.

Our study also identified occupation such as 'farmer' showed good PHH performance compared with 'clerk' or 'freelancer'. We did not found the similar findings in other studies, the reasons for which may be need to be further explored.

Our study has several limitations. First, since this is a single-centre cross-sectional survey, our results may not be applicable to all other institutions. Thus, it is recommended that a multicentre study with a large sample size be conducted in the future. Second, our inclusion of certain patients and wards may have resulted in selection bias. Physically weak patients were also recruited in the present study, and their families or caregivers filled out the questionnaire; therefore, there is a possibility that the family members of caregivers may have provided information on their own $\mathrm{HH}$ situation rather than that of the patients. Therefore, there is a need for further observational studies including quantitative hand bacterial cultures to verify the results of this study. Nonetheless, we believe that this study included a representative sample of inpatients. Third, the study was conducted using a convenience sampling method in the category of family members. Finally, although the survey findings are interesting, the patients appear to know that $\mathrm{HH}$ is important even though they know little about HH knowledge, the social desirability factor might be operating, the results are not an indicator of how patients may actually behave in real life.

\section{CONCLUSIONS}

In conclusion, this study demonstrated that patients had a positive attitude towards HH. However, their levels of knowledge and practice were unsatisfactory. These results suggest that A systematical education about $\mathrm{PHH}$ is needed in future to correct this knowledge and behaviour. In addition, special attention should be given to those $\mathrm{HH}$ moments the compliance rates to which were the lowest, such as before drinking fluids, as well as before interacting with visitors and after they leave.

Acknowledgements The authors thank Li Hao RN, Luo Zi-zhao RN, Zhong Xu RN, Luo Yan RN and Hu Chun-Ping RN for their assistance with data collection, as well as the ward nurse leaders, nursing staff and patients of the hospital for their willingness to participate. We also would like to thank Editage (www.editage.cn) for English language editing.

Contributors YXL and SEY contributed to the study conception and design, data collection, analysis, interpretation and drafting the manuscript. YHL and LZ contributed to questionnaire design and data collection. YHL and CC contributed to the data collection and data management. DM contributed to the study design, data acquisition and interpretation. All authors contributed to drafting the manuscript and critically revised the manuscript and approved the final version.

Funding The authors have not declared a specific grant for this research from any funding agency in the public, commercial or not-for-profit sectors.

Competing interests None declared.

Patient consent for publication Not required.

Ethics approval The study was approved by the Institutional Review Board of Xiangya Hospital, Central South University (No 201708955).

Provenance and peer review Not commissioned; externally peer reviewed.

Data sharing statement Extra data can be extracted by emailing the corresponding author SY.

Open access This is an open access article distributed in accordance with the Creative Commons Attribution Non Commercial (CC BY-NC 4.0) license, which permits others to distribute, remix, adapt, build upon this work non-commercially, and license their derivative works on different terms, provided the original work is properly cited, appropriate credit is given, any changes made indicated, and the use is non-commercial. See: http://creativecommons.org/licenses/by-nc/4.0/.

\section{REFERENCES}

1. Seymour CW, Liu VX, Iwashyna TJ, et al. Assessment of clinical criteria for sepsis: for the third international consensus definitions for sepsis and septic shock (Sepsis-3). JAMA 2016;315:762-74.

2. Fleischmann C, Scherag A, Adhikari NK, et al. Assessment of global incidence and mortality of hospital-treated sepsis. current estimates and limitations. Am J Respir Crit Care Med 2016;193:259-72.

3. Boyce JM, Pittet D, Healthcare Infection Control Practices Advisory Committee. Society for Healthcare Epidemiology of America. Association for Professionals in Infection Control. Infectious Diseases Society of America. Hand Hygiene Task Force. Guideline for Hand Hygiene in Health-Care Settings: recommendations of the Healthcare Infection Control Practices Advisory Committee and the HICPAC/ SHEA/APIC/IDSA Hand Hygiene Task Force. Infect Control Hosp Epidemiol 2002;23:S3-S40.

4. Pittet D, Allegranzi B, Boyce J. The world health organization guidelines on hand hygiene in health care and their consensus recommendations. Infect Control Hosp Epidemiol 2009;30:611-22.

5. Saito H, Borzykowski T, Kilpatrick C, et al. "It's in your hands prevent sepsis in health care"; 5 May 2018 World Health Organization (WHO) SAVE LIVES: Clean Your Hands campaign. Am J Infect Control 2018:1-2.

6. Meng X, Liu S, Duan J, et al. Risk factors and medical costs for healthcare-associated carbapenem-resistant Escherichia coli infection among hospitalized patients in a Chinese teaching hospital. BMC Infect Dis 2017;17:82.

7. Li C, Duan J, Liu S, et al. Assessing the risk and disease burden of Clostridium difficile infection among patients with hospital-acquired 
pneumonia at a University Hospital in Central China. Infection 2017;45:621-8.

8. Cao WW, Zhou RR, Ou X, et al. Prevalence of hepatitis B virus, hepatitis $C$ virus, human immunodeficiency virus and Treponema pallidum infections in hospitalized patients before transfusion in Xiangya hospital Central South University, China from 2011 to 2016. BMC Infect Dis 2018;18:145.

9. Landers T, Abusalem S, Coty MB, et al. Patient-centered hand hygiene: the next step in infection prevention. Am J Infect Control 2012;40:S11-S17.

10. . https://www.cdc.gov/handwashing/when-how-handwashing.html

11. Alzyood $M$, Jackson $D$, Brooke J, et al. An integrative review exploring the perceptions of patients and healthcare professionals towards patient involvement in promoting hand hygiene compliance in the hospital setting. J Clin Nurs 2018;27:1329-45.

12. National Health Commission of the People's Republic of China. "Standard for hand hygiene for healthcare workers in healthcare settings" [S]. [2009-04-01/ 2009-12-01]. http://www.nhfpc.gov. cn/zhuz/s9496/200904/40118/files/5fe4afce5b874512a9780c72 4a4d5be0.pdf

13. Cheng VC, Tai JW, Li WS, et al. Implementation of directly observed patient hand hygiene for hospitalized patients by hand hygiene ambassadors in Hong Kong. Am J Infect Control 2016;44:621-4.

14. World Health Organization. A guide to the implementation of the WHO multimodal hand hygiene improvement strategy. Geneva, Switzerland: World Health Organization, 2009.

15. Taylor LJ. An evaluation of handwashing techniques-2. Nurs Times 1978;74:108-10.

16. Ardizzone LL, Smolowitz J, Kline N, et al. Patient hand hygiene practices in surgical patients. Am J Infect Control 2013;41:487-91.

17. Pokrywka M, Buraczewski M, Frank D, et al. Can improving patient hand hygiene impact Clostridium difficile infection events at an academic medical center? Am J Infect Control 2017;45:959-63.

18. Huang GK, Stewardson AJ, Grayson ML. Back to basics: hand hygiene and isolation. Curr Opin Infect Dis 2014;27:379-89.

19. Wilkinson MAC, Kiernan MA, Wilson JA, et al. Assessment of the efficacy of a patient hand wipe: development of a test method. $J$ Hosp Infect 2018;98:339-44.
20. Srigley JA, Furness CD, Gardam M. Measurement of patient hand hygiene in multiorgan transplant units using a novel technology: an observational study. Infect Control Hosp Epidemiol 2014;35:1336-41.

21. Knighton SC, Dolansky M, Donskey C, et al. Use of a verbal electronic audio reminder with a patient hand hygiene bundle to increase independent patient hand hygiene practices of older adults in an acute care setting. Am J Infect Control 2018;46:610-6.

22. Rai H, Knighton S, Zabarsky TF, et al. Comparison of ethanol hand sanitizer versus moist towelette packets for mealtime patient hand hygiene. Am J Infect Control 2017;45:1033-4.

23. Birnbach DJ, Rosen LF, Fitzpatrick M, et al. An evaluation of hand hygiene in an intensive care unit: Are visitors a potential vector for pathogens? J Infect Public Health 2015;8:570-4.

24. Okada J, Yamamizu Y, Fukai K. Effectiveness of hand hygiene depends on the patient's health condition and care environment. Jpn J Nurs Sci 2016;13:413-23.

25. Randle J, Arthur A, Vaughan N. Twenty-four-hour observational study of hospital hand hygiene compliance. J Hosp Infect 2010;76:252-5

26. Lei JH, Guo YJ, Chen Z, et al. Problem/case-based learning with competition introduced in severe infection education: an exploratory study. Springerplus 2016;5.

27. Xie J, Ming Y, Ding S, et al. Rising Need for Health Education Among Renal Transplant Patients and Caregiving Competence in Care Providers. Prog Transplant 2017;27:180-6.

28. Scheithauer S, Oude-Aost J, Heimann K, et al. Hand hygiene in pediatric and neonatal intensive care unit patients: daily opportunities and indication- and profession-specific analyses of compliance. Am $J$ Infect Control 2011;39:732-7.

29. He L, Meng J, Huang D, et al. [Multidrug-resistant Acinetobacter Baumannii infection in Intensive Care Unit: A retrospective analysis]. Zhong Nan Da Xue Xue Bao Yi Xue Ban 2015;40:1327-32.

30. Zhou P, Xiong X, Li C, et al. Association of Length of Stay With Contamination of Multidrug-Resistant Organisms in the Environment and Colonization in the Rectum of Intensive Care Unit Patients in China. Infect Control Hosp Epidemiol 2016;37:120-1. 